\title{
CYP2D6 genotype- and endoxifen-guided tamoxifen dose escalation increases endoxifen serum concentrations without increasing side effects
}

\author{
V. O. Dezentjé $e^{1,2} \cdot$ F. L. Opdam ${ }^{1,2} \cdot$ H. Gelderblom ${ }^{1} \cdot$ J. Hartigh den ${ }^{2} \cdot$ \\ T. Van der Straaten ${ }^{2} \cdot$ R. Vree ${ }^{3}$ E. Maartense ${ }^{4}$ - C. H. Smorenburg ${ }^{5}$. \\ H. Putter ${ }^{6}$ A. S. Dieudonné ${ }^{7} \cdot$ P. Neven ${ }^{7}$ - C. J. H. Van de Velde ${ }^{8}$. \\ J. W. R. Nortier ${ }^{1} \cdot$ H.-J. Guchelaar ${ }^{2}$
}

Received: 12 June 2015/ Accepted: 1 September 2015/Published online: 14 September 2015

(C) The Author(s) 2015. This article is published with open access at Springerlink.com

\begin{abstract}
Breast cancer patients with absent or reduced CYP2D6 activity and consequently low endoxifen levels may benefit less from tamoxifen treatment. CYP2D6 poor and intermediate metabolizers may need a personalized increased tamoxifen dose to achieve effective endoxifen serum concentrations, without increasing toxicity. From a prospective study population of early breast cancer patients using tamoxifen (CYPTAM: NTR1509), 12 CYP2D6 poor and 12 intermediate metabolizers were selected and included in a one-step tamoxifen dose escalation study
\end{abstract}

V. O. Dezentjé, F. L. Opdam contributed equally to the manuscript.

Electronic supplementary material The online version of this article (doi:10.1007/s10549-015-3562-5) contains supplementary material, which is available to authorized users.

V. O. Dezentjé

v.dezentje@gmail.com

1 Department of Clinical Oncology, Leiden University Medical Center, Leiden, The Netherlands

2 Department of Clinical Pharmacy \& Toxicology, Leiden University Medical Center, Leiden, The Netherlands

3 Department of Surgery, Diaconessenhuis, Leiden, The Netherlands

4 Department of Internal Medicine, Reinier de Graaf Groep, Delft, The Netherlands

5 Department of Internal Medicine, Medical Center Alkmaar, Alkmaar, The Netherlands

6 Department of Medical Statistics, Leiden University Medical Center, Leiden, The Netherlands

7 Department of Gynaecologic Oncology, University Hospitals Leuven, Louvain, Belgium

8 Department of Surgery, Leiden University Medical Center, Leiden, The Netherlands during 2 months. The escalated dose was calculated by multiplying the individual's endoxifen level at baseline relative to the average endoxifen concentration observed in CYP2D6 extensive metabolizers by $20 \mathrm{mg}$ (120 mg maximum). Endoxifen levels and tamoxifen toxicity were determined at baseline and after 2 months, just before patients returned to the standard dose of $20 \mathrm{mg}$. Tamoxifen dose escalation in CYP2D6 poor and intermediate metabolizers significantly increased endoxifen concentrations ( $p<0.001 ; p=0.002$, respectively) without increasing side effects. In intermediate metabolizers, dose escalation increased endoxifen to levels comparable with those observed in extensive metabolizers. In poor metabolizers, the mean endoxifen level increased from 24 to $81 \%$ of the mean concentration in extensive metabolizers. In all patients, the endoxifen threshold of $5.97 \mathrm{ng} / \mathrm{ml}(=16.0 \mathrm{nM})$ reported by Madlensky et al. was reached following dose escalation. CYP2D6 genotype- and endoxifen-guided tamoxifen dose escalation increased endoxifen concentrations without increasing short-term side effects. Whether such tamoxifen dose escalation is effective and safe in view of long-term toxic effects is uncertain and needs to be explored.

Keywords CYP2D6 - Endoxifen - Early breast cancer

\section{Introduction}

In 2005, Goetz et al. reported the first study in which a positive association was found between the cytochrome P450 2D6 isoenzyme (CYP2D6) genotype and tamoxifen efficacy in early breast cancer patients [1]. Previously, it was demonstrated that genetic variants of CYP2D6, leading to an enzyme with impaired or absent activity, resulted in 
lower blood concentrations of the most important active tamoxifen metabolite, endoxifen [2,3]. At present, the discussion whether CYP2D6 activity is a relevant predictor of tamoxifen response is still timely, although conflicting data have created much controversy [1, 4-12]. The variance of endoxifen blood concentrations among the separate CYP2D6 phenotypes (poor (PM), intermediate (IM), extensive (EM), and ultrarapid metabolizers (UM)) is large and may have contributed to these conflicting data. The CYP2D6 genotype only partially predicts endoxifen blood levels $\left(r^{2}=23-43 \%\right)$; therefore, endoxifen concentration itself may be a better predictor of tamoxifen response [3, 13]. Many studies have investigated the in vitro effects of endoxifen leading to the general belief that endoxifen is the most important active tamoxifen metabolite [2, 3, 14-16]. However, no prospective study to date has directly addressed the possible association between endoxifen blood levels in patients and efficacy. In the Women's Healthy Eating and Living (WHEL) study, the first retrospective correlation between endoxifen concentration and breast cancer survival was made [17]. Patients with endoxifen levels in the range of the lowest quintile had a $35 \%$ higher rate of breast cancer events suggesting a threshold effect with a reported endoxifen threshold of $5.97 \mathrm{ng} / \mathrm{ml}(=16.0 \mathrm{nM})$. In this study, $76 \%$ of the CYP2D6 poor metabolizers had endoxifen levels within the range of the lowest quintile. This study, however, was not designed for this purpose and the borderline significant difference in outcome between the patients with the lowest endoxifen levels (lowest quintile) and the patients with higher endoxifen levels $(\mathrm{HR}=0.74$; $95 \%$ CI $0.55-1.00$ ) should be interpreted with caution. Patients with low endoxifen blood concentrations may experience less tamoxifen efficacy and may require a tamoxifen dose higher than the standard $20 \mathrm{mg}$ once daily dose. In contrast, increasing the tamoxifen dosage to $90 \mathrm{mg}$ daily did not affect tamoxifen response in metastatic breast cancer patients compared to a standard dose of $30 \mathrm{mg}$ daily with equal response rate and duration. The investigators of this small study however did not account for CYP2D6 genotype or endoxifen level [18]. CYP2D6 intermediate and poor metabolizers with low endoxifen levels may still benefit from higher tamoxifen doses.

In a recent study, the feasibility of increasing endoxifen concentration in intermediate (IMs) and poor metabolizers (PMs) was demonstrated [19]. By increasing the $20 \mathrm{mg}$ tamoxifen dose in IMs and PMs to $40 \mathrm{mg}$ once daily, endoxifen levels were significantly increased. The increased endoxifen levels in IMs using $40 \mathrm{mg}$ tamoxifen did not significantly differ with the endoxifen concentration found in extensive metabolizers (EMs) using the standard dosage, while the increased endoxifen levels in the dose escalated PMs were still significantly lower. Therefore, PMs and some IMs may need more than a double tamoxifen dose in order to reach the mean endoxifen level found in EMs. How to calculate the necessary tamoxifen dose and whether higher doses of tamoxifen can be safely used to reach this goal is unknown. In metastatic breast cancer and other advanced tumor types, a tamoxifen dose up to $120 \mathrm{mg}$ daily seems tolerable with limited side effects during a short period of time [18, 20-24].

In The Netherlands and Belgium, a prospective study (CYPTAM study: NTR1509) has included 650 early breast cancer patients using tamoxifen to relate predicted CYP2D6 phenotype and endoxifen serum concentration to disease-free survival [25]. Patients with a CYP2D6 poor or intermediate metabolizer phenotype who were still treated with tamoxifen could be included in a pharmacokinetic study. The aim of the current pharmacokinetic study is to investigate the effect of a temporary one-step tamoxifen dose escalation on endoxifen serum concentration and toxicity in poor and intermediate metabolizers.

\section{Methods}

\section{Patients}

From February 2008 until December 2010, 650 early breast cancer patients who were using tamoxifen as a part of an adjuvant treatment were included in a multicenter study in The Netherlands and Belgium aiming to relate CYP2D6predicted phenotype and endoxifen serum concentrations to breast cancer survival (CYPTAM study) [25]. These patients were genotyped for genetic variants in the CYP2D6 gene and were classified into an ultrarapid (UM), extensive (EM), intermediate (IM), or poor metabolizer (PM) CYP2D6 phenotype. Pre- and postmenopausal women ( $\geq 18$ years) with hormone receptor positive early breast cancer treated with adjuvant tamoxifen after tumor resection were eligible for the subsequent pharmacokinetic study if they had no medical history of another malignancy or a venous thromboembolic event, were not pregnant or breastfeeding, had a normal QT-interval on ECG registration, hemoglobin $\geq 6.0 \mathrm{mmol} / \mathrm{L}, \quad W B C \geq 3.0 \times 109 / \mathrm{L}$, platelets $\geq 100 \times 109 / \mathrm{L}$, bilirubin within normal limits, ASAT and ALAT $\leq 2.5$ times the upper limit of normal, and if they had a poor or intermediate metabolizer phenotype (12 PMs and $12 \mathrm{IMs}$ ). Patients should be using tamoxifen for more than 2 months. Concomitant use of a CYP2D6 inhibitor was permitted.

\section{CYP2D6 predicted phenotype}

CYP2D6 genotyping was performed using the Amplichip CYP450 test (Roche Diagnostics, Indianapolis, US) to test the major CYP2D6 alleles (33) on whole blood. CYP2D6 
genotypes were translated to predicted phenotypes (ultrarapid (UM), extensive (EM), intermediate (IM), or poor metabolizer (PM)). By definition, the CYP2D6 IM phenotype predicted by genotype consisted of patients homozygous for a decreased activity allele (e.g., $* 41 / * 41$ ) or heterozygous for an absent activity allele (e.g., $* 1 / * 4$ and $* 41 / * 4)$. In contrast, the Amplichip test translates the genotype with one absent and one normal activity allele (e.g., *1/*4) into an EM phenotype. This genotype is sometimes translated into a heterozygous extensive metabolizer phenotype (hetEM). Previously, we have shown that hetEM is a distinct phenotype with a mean endoxifen level in between the extensive and true intermediate metabolizer phenotype [13]. Additionally, concomitant use of a CYP2D6 inhibitor could reclassify the CYP2D6 phenotype predicted by genotype [26].

\section{Study design}

After enrollment in the CYPTAM study, whole blood and serum samples were retrieved for CYP2D6 genotyping and measurement of tamoxifen and its metabolites after $\geq 2$ months of tamoxifen use, ensuring steady state endoxifen levels. The time interval between serum sample retrieval and the last tamoxifen intake had to be more than $12 \mathrm{~h}$ to obtain endoxifen trough levels. Patients with a CYP2D6 PM and IM phenotype were informed and asked to participate in a genotype-directed dose escalation study until 12 patients were included from each phenotype group and initiated the tamoxifen dose escalation. Inclusion only took place after written-informed consent was obtained at the Leiden University Medical Center. All patients were initially treated with the standard dose of $20 \mathrm{mg}$ tamoxifen once daily. The 12 PMs and 12 IMs included in the pharmacokinetics study participated in a temporary one-step tamoxifen dose escalation during 2 months. The individual patient's baseline endoxifen serum concentration was determined by calculating the mean of two separate endoxifen measurements in time. Previously, the average endoxifen serum concentration in EMs of $33.7 \mathrm{nM}$ (7.2-87.3) was determined by using the median endoxifen level in the first 586 patients included in the CYPTAM documentation study just before initiating the pharmacokinetics study at that time consisting of 292 EMs [13]. Based on the pharmacokinetics of other metabolites, during different low doses of tamoxifen up to $20 \mathrm{mg}$, we hypothesized that endoxifen levels would also be linearly increased by further escalating the tamoxifen dose [27]. As a linear increase in endoxifen plasma concentration was assumed with increasing tamoxifen doses, the individual tamoxifen escalation dose was calculated by the formula: $20 \mathrm{mg} \times$ (average endoxifen serum concentration in EMs/patient's baseline endoxifen serum concentration). The tamoxifen escalation dose was limited to a maximal dose of
$120 \mathrm{mg}$ once daily for reasons of safety. Calculated escalation dosage was rounded off upwards or downwards to every $10 \mathrm{mg}$. Patients were instructed to use the tamoxifen escalation dose for the duration of 2 months until the next determination of endoxifen serum concentration or earlier if severe toxicity occurred. After 2 months of using the increased tamoxifen dose, a next serum sample was retrieved, and the patient returned to the standard daily dose of $20 \mathrm{mg}$. Toxicity was assessed at 1,2, and 3 months after the starting date of the tamoxifen dose escalation using the National Cancer Institute Common Toxicity Criteria for Adverse Events, version 3.0. ECGs were made, and blood samples were drawn for serum biochemistry and hematology at baseline, and at 2 months of dose escalation. The current study was approved by the central medical ethics review board of the Leiden University Medical Center in Leiden, The Netherlands. All patients gave written-informed consent before entering the study.

\section{Tamoxifen and metabolite measurement}

Serum concentrations of tamoxifen and its metabolites were measured by using a high-performance liquid chromatography-tandem mass spectrometry (HPLC LC/MS/ MS) assay for the detection of tamoxifen and three metabolites in human serum. The HPLC LC/MS/MS assay was developed and validated for the purpose of the CYPTAM study at the laboratory of Clinical Pharmacy and Toxicology at the Leiden University Medical Center and is similar to a previously described method [28]. Tamoxifen, $\mathrm{N}$-desmethyltamoxifen (NDMTam), and the main active metabolites 4-hydroxytamoxifen (4OHTam) and 4-hydroxy- $N$-desmethyltamoxifen (endoxifen) were accurately detected and quantified (Fig. 1).

\section{Statistical methods}

Tamoxifen, NDMTam, 4OHTam, and endoxifen serum concentrations were measured three times in PMs and IMs: (1) at entering the CYPTAM study, (2) before tamoxifen dose escalation and (3) at 2 months of dose escalation. A paired $T$ test was used to test the null hypothesis that the change in concentration of endoxifen and other tamoxifen metabolites at 2 months of dose escalation from baseline equals zero. A one sample $T$ test was used to test the difference between endoxifen serum concentration at 2 months of tamoxifen dose escalation in PMs and IMs and the median endoxifen level in EMs without dose escalation $(33.7 \mathrm{nM})$. Side effects were dichotomized (hot flushes: grade $0-1$ vs. $2-3$, other side effects: grade 0 vs. grade $\geq 1$ ), and the difference between side effects before and at 2 months of dose escalation were tested using the McNemar's Chi-squared test. 
Fig. 1 Tamoxifen metabolism. 4OHTam 4-hydroxytamoxifen, CYP cytochrome $\mathrm{P} 450$ isoenzyme, $S U L T$ sulfotransferase, UGT UDPglucuronosyltransferase, NDMTam N-

desmethyltamoxifen, NRI nuclear receptor subfamily 1 , $P X R$ pregnane $\mathrm{X}$ receptor, $C A R$ constitutive androstane receptor
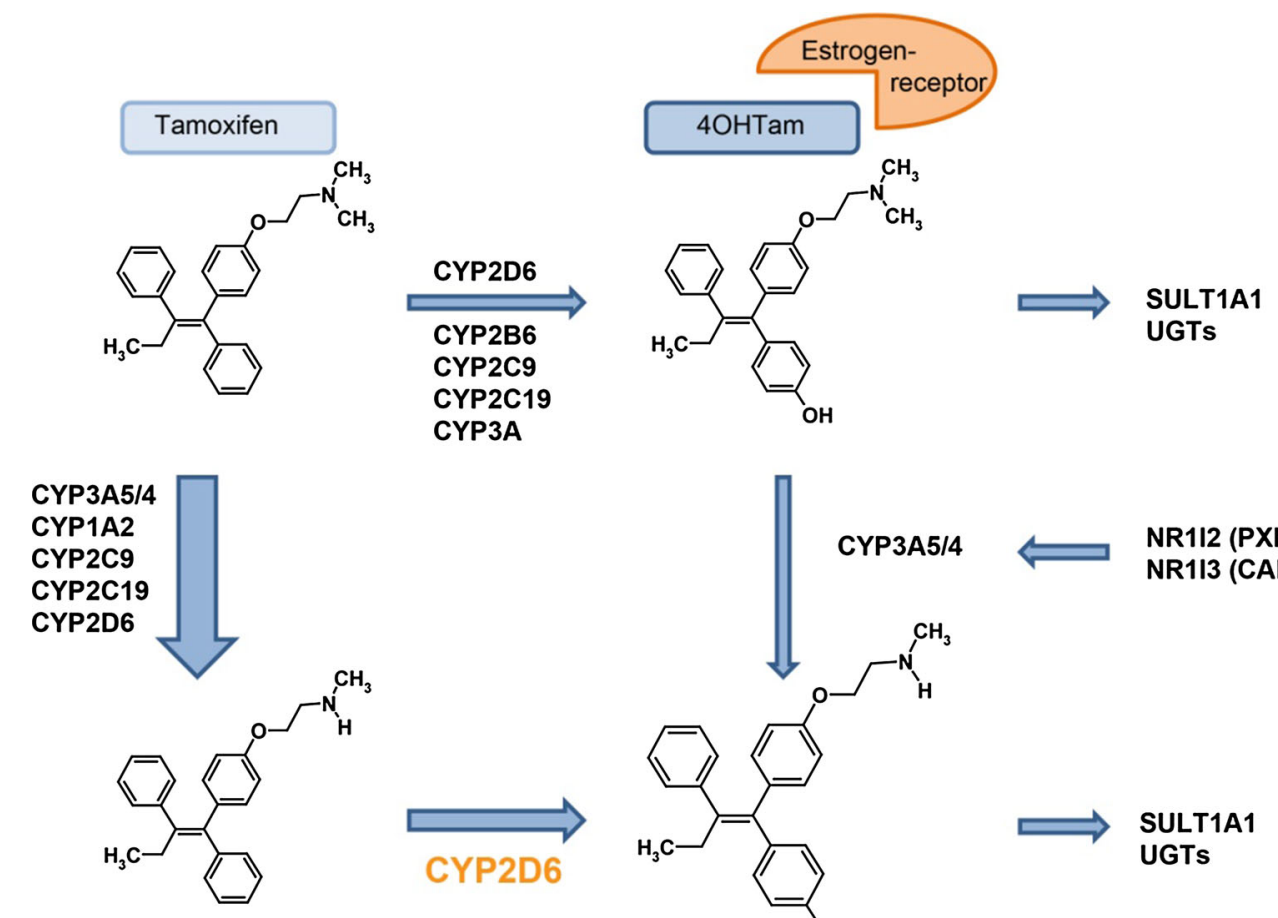

NDMTam

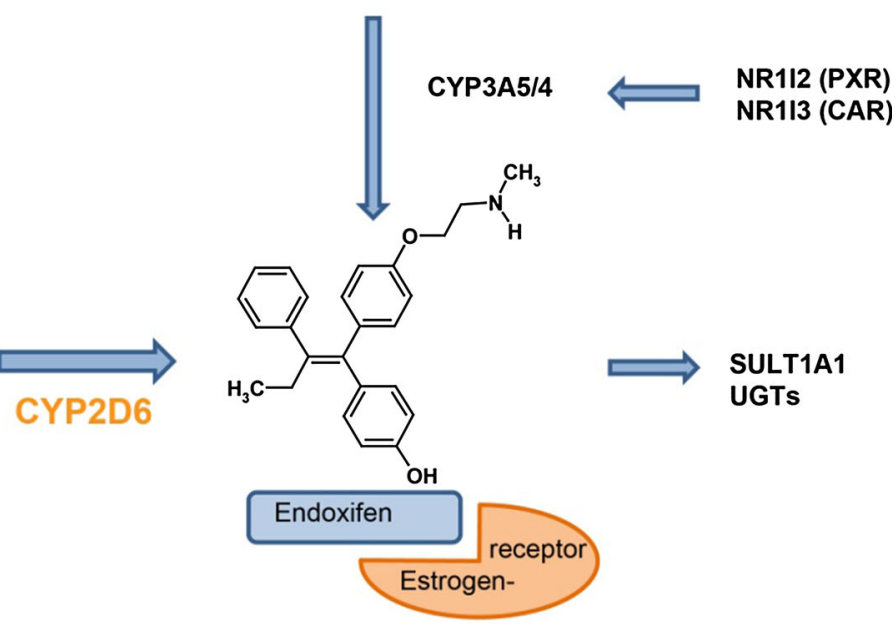

\section{Results}

In the current pharmacokinetics study, 12 PMs and 12 IMs were included and started dose escalation. The baseline characteristics of these 24 patients are shown in Table 1. Most patients were postmenopausal, three IMs and one PM were premenopausal. Mean age was 53.9 years for PMs

and 52.4 years for IMs. The mean BMI was notably higher in PMs than in IMs $\left(29.4\right.$ and $\left.26.7 \mathrm{~kg} / \mathrm{m}^{2}\right)$. One patient used venlafaxine, a weak CYP2D6 inhibitor. Another patient used paroxetine, a strong CYP2D6 inhibitor during tamoxifen use. All patients were using tamoxifen for more than 2 months ensuring steady state concentrations of tamoxifen and its metabolites (mean 22.5 months, range

Table 1 Baseline characteristics of 24 early breast cancer patients

\begin{tabular}{|c|c|c|}
\hline & \multicolumn{2}{|l|}{ CYP2D6 phenotype } \\
\hline & $\mathrm{IM}(n=12)$ & $\mathrm{PM}(n=12)$ \\
\hline Mean age in years (range; SD) & $52.4(41.5-71.0 ; 8.7)$ & $53.9(40.7-67.7 ; 8.0)$ \\
\hline Mean BMI in kg/m² (range; SD) & $26.7(20.6-34.5 ; 4.2)$ & $29.4(21.0-42.8 ; 6.7)$ \\
\hline \multicolumn{3}{|l|}{ Menopausal status } \\
\hline Premenopausal & 3 & 1 \\
\hline Postmenopausal & 8 & 11 \\
\hline Unknown & 1 & 0 \\
\hline Mean tamoxifen duration in months (range) & $23.3(14.0-56.6)$ & $21.8(12.0-34.7)$ \\
\hline \multirow[t]{4}{*}{ CYP2D6 genotypes } & $* 1 / * 4(n=2)$ & $* 3 / * 4(n=2)$ \\
\hline & $* 2 / * 4(n=6)$ & $* 4 / * 4(n=7)$ \\
\hline & $* 2 / * 5(n=2)$ & $* 4 / * 5(n=2)$ \\
\hline & $* 4 / * 41(n=2)$ & $* 5 / * 6$ \\
\hline CYP2D6 inhibitor use & 1 (venlafaxine) & 1 (paroxetine) \\
\hline
\end{tabular}

$I M$ intermediate metabolizer, $P M$ poor metabolizer, $n$ number of patients, $S D$ standard deviation 
12.0-56.6 months). Of the 12 PMs who started dose escalation, one stopped after $\sim 2$ weeks because of toxicity at a tamoxifen dose of $60 \mathrm{mg}$. One PM completed the 2 months of $90 \mathrm{mg}$ dose escalation; unfortunately, the last serum sample was not properly obtained. Thus, for the comparison of endoxifen and other metabolite concentration before and at 2 months of dose escalation, 22 patients were analyzed. Toxicity was evaluated in 24 patients.

The mean tamoxifen escalation dose for the 12 IMs was $46 \mathrm{mg}$ (range 30-100 mg) and $90 \mathrm{mg}$ (range 60-120 mg) for 10 PMs, who all completed the 2 months dose escalation (Table 2). The endoxifen serum concentrations in both PMs and IMs were significantly increased compared to the concentrations measured at baseline (PMs: from $8.0 \mathrm{nM}$ to $27.3 \mathrm{nM}, p<0.001$; IMs: from $17.8 \mathrm{nM}$ to $30.3 \mathrm{nM}$, $p=0.002$ ) as shown in Table 2 and Fig. 2. Compared to the median endoxifen concentration in EMs using a normal $20 \mathrm{mg}$ tamoxifen dose $(=33.7 \mathrm{nM})$, there was no significant difference with the mean endoxifen level after dose escalation in IMs $(=30.3 \mathrm{nM} ; p=0.20)$, although the mean endoxifen level in PMs after dose escalation was significantly lower $(=27.3 \mathrm{nM} ; p=0.03)$ as shown in Table 2. Serum tamoxifen and the other metabolites were also significantly increased following dose escalation (Supplementary Table 4).

Toxicity resulted in premature cessation of the escalated dose in one patient using tamoxifen at a dose of $60 \mathrm{mg}$, although side effects were $\leq$ grade 2 (grade 1 hot flashes and diarrhea, grade 2 headache, dizziness, and fatigue). One patient using $50 \mathrm{mg}$ of tamoxifen experienced a bothersome grade 2 tendinitis of one of her fingers. On ECG, the QTc in one patient using $100 \mathrm{mg}$ tamoxifen was slightly prolonged at 2 months (464 ms vs. $435 \mathrm{~ms}$ at baseline) but normalized 2 weeks after returning to the $20 \mathrm{mg}$ dose (QTc $=436 \mathrm{~ms})$. No grade 3 or 4 toxicity was observed as a result of the dose escalation: only one patient already had grade 3 hot flashes at baseline. Remarkably, in 4 patients, grade 1 hot flashes disappeared during dose escalation. In two of these patients, grade 1 hot flashes reappeared 1 month after returning to the normal dose.
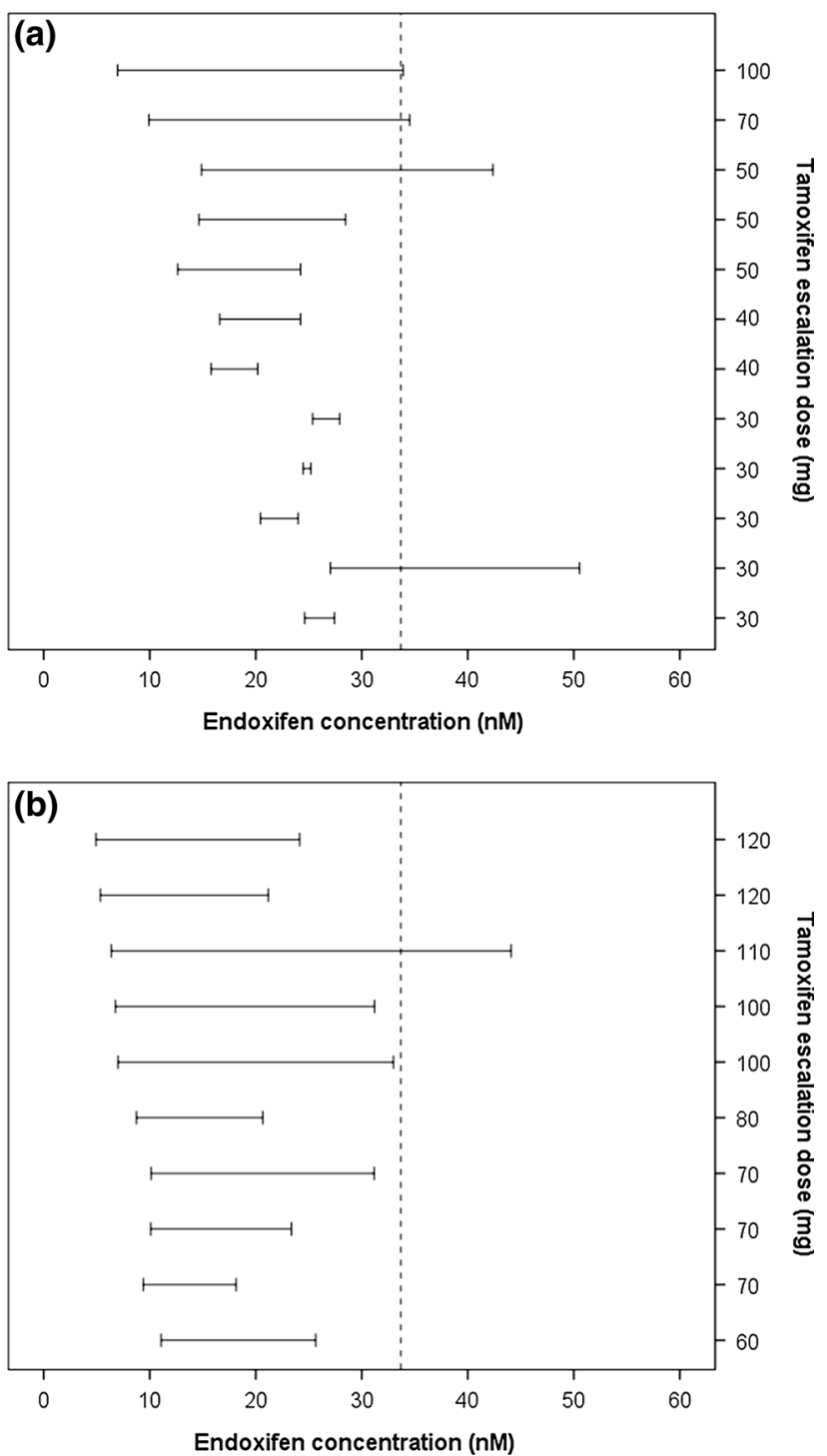

Fig. 2 Endoxifen concentration before and after tamoxifen dose escalation during 2 months in $\mathbf{a}$ intermediate metabolizers and $\mathbf{b}$ poor metabolizers. Each line represents one patient, starting with a baseline [endoxifen] on the left, which increases to an [endoxifen] after 2 months of dose escalation on the right. Median [endoxifen] in extensive metabolizers used for calculating the tamoxifen escalation dose. a Intermediate metabolizers, $\mathbf{b}$ poor metabolizers

Table 2 Serum endoxifen concentrations in IMs and PMs after tamoxifen dose escalation compared to the median serum endoxifen concentration in EMs $(33.7 \mathrm{nM})$

\begin{tabular}{llllll}
\hline $\begin{array}{l}\text { CYP2D6 } \\
\text { phenotype }\end{array}$ & $n$ & $\begin{array}{l}\text { [Endoxifen] before } \\
\text { dose escalation } \\
\text { (range; SD) }\end{array}$ & $\begin{array}{l}\text { Mean escalated } \\
\text { tamoxifen dose } \\
\text { (range) }\end{array}$ & $\begin{array}{l}\text { [Endoxifen] after } \\
\text { dose escalation } \\
\text { (range; SD) }\end{array}$ & $\begin{array}{l}\text { [Endoxifen] after } \\
\text { dose escalation } \\
\text { vs. 33.7 nM in EMs }\end{array}$ \\
\hline $\mathrm{IM}$ & 12 & $17.8 \mathrm{nM}(7.0-27.0 ; 6.5)$ & $46 \mathrm{mg}(30-100)$ & $30.3 \mathrm{nM}^{\mathrm{a}}(20.2-50.6 ; 8.8)$ & $p=0.20$ \\
$\mathrm{PM}$ & 10 & $8.0 \mathrm{nM}(4.9-11.1 ; 2.2)$ & $90 \mathrm{mg}(60-120)$ & $27.3 \mathrm{nM}^{\mathrm{b}}(18.2-44.1 ; 7.7)$ & $p=0.03$ \\
\hline
\end{tabular}

$I M$ intermediate metabolizer, $P M$ poor metabolizer, $n$ number of patients, $S D$ standard deviation

${ }^{a}$ Significant increase compared to baseline [endoxifen]; $p<0.001$

b Significant increase compared to baseline [endoxifen]; $p=0.002$ 
Nearly all side effects that increased during tamoxifen escalation returned to baseline values 1 month after cessation of the tamoxifen escalation. No significant differences were found between side effects at baseline and at 2 months of dose escalation (Table 3 ). Only a nonsignificant increase in grade 1 fatigue $(p=0.13)$ and grade 1 alopecia $(p=0.25)$ was observed.

\section{Discussion}

In the current CYP2D6 genotype- and endoxifen-guided dose escalation study, we temporarily increased the tamoxifen dose in CYP2D6 intermediate and poor metabolizers in one step to a daily dose of up to $120 \mathrm{mg}$. This is the first study in which the tamoxifen dose is escalated by using a calculation, based on individual endoxifen concentration at baseline: thus, an individual dose adaptation was made. In previous studies, the tamoxifen dose in poor and intermediate metabolizers was escalated from 20 up to $40 \mathrm{mg}$, but not in such a personalized manner as described here $[19,29,30]$. Of note, a better recurrencefree survival but not overall survival was demonstrated in the Oxford overview when using $40 \mathrm{mg}$ instead of $20 \mathrm{mg} /$ day [31].

Our endoxifen-guided dose escalation resulted in a significant increase of endoxifen serum concentrations in both IMs and PMs. In IMs but not in PMs, dose escalation increased endoxifen to levels comparable with those observed in extensive metabolizers. The endoxifen increase in poor metabolizers is higher than expected from a capacity-limited metabolism with saturation of CYP2D6, especially when CYP2D6 activity is low or even absent. An explanation for the more than threefold increase in
Table 3 Comparison between side effects at baseline and 2 months of tamoxifen dose escalation in 12 IMs and 11 PMs

\begin{tabular}{|c|c|c|c|c|c|}
\hline \multirow[t]{2}{*}{ Adverse effect } & \multicolumn{2}{|l|}{ Baseline } & \multicolumn{2}{|l|}{+2 Months } & \multirow{2}{*}{$\begin{array}{l}\text { McNemar's test } \\
p \text { value }\end{array}$} \\
\hline & Grade $0-1$ & Grade $\geq 2$ & Grade $0-1$ & Grade $\geq 2$ & \\
\hline \multicolumn{6}{|l|}{ Hot flashes } \\
\hline IM & 11 & 1 & 9 & 3 & 0.50 \\
\hline $\mathrm{PM}$ & 11 & 0 & 10 & 1 & $-{ }^{\mathrm{a}}$ \\
\hline \multirow[t]{2}{*}{ All } & 22 & 1 & 19 & 4 & 0.25 \\
\hline & Grade 0 & Grade $\geq 1$ & Grade 0 & Grade $\geq 1$ & \\
\hline \multicolumn{6}{|l|}{ Headache } \\
\hline All & 20 & 3 & 21 & 2 & 1.00 \\
\hline \multicolumn{6}{|l|}{ Dizziness } \\
\hline All & 22 & 1 & 21 & 2 & 1.00 \\
\hline \multicolumn{6}{|l|}{ Nausea } \\
\hline All & 22 & 1 & 21 & 2 & 1.00 \\
\hline \multicolumn{6}{|l|}{ Alopecia } \\
\hline IM & 11 & 1 & 11 & 1 & 1.00 \\
\hline PM & 9 & 2 & 6 & 5 & 0.25 \\
\hline All & 20 & 3 & 17 & $6^{\mathrm{b}}$ & 0.38 \\
\hline \multicolumn{6}{|c|}{ Vaginal discharge } \\
\hline All & 21 & 2 & 21 & 2 & 1.00 \\
\hline \multicolumn{6}{|l|}{ Vaginal dryness } \\
\hline All & 21 & 2 & 21 & 2 & 1.00 \\
\hline \multicolumn{6}{|l|}{ Fatigue } \\
\hline IM & 9 & 3 & 6 & 6 & 0.25 \\
\hline $\mathrm{PM}$ & 9 & 2 & 8 & 3 & 1.00 \\
\hline All & 18 & 5 & 14 & $9^{\mathrm{b}}$ & 0.13 \\
\hline \multicolumn{6}{|l|}{ Ocular } \\
\hline All & 23 & 0 & 21 & 2 & $-{ }^{\mathrm{a}}$ \\
\hline \multicolumn{6}{|l|}{ Musculoskeletal } \\
\hline All & 19 & 4 & 20 & 3 & 1.00 \\
\hline
\end{tabular}

$I M$ intermediate metabolizer, $P M$ poor metabolizer

${ }^{a}$ Unable to calculate $p$ value

b All grade 1 
endoxifen concentration in PMs may be that other routes leading to endoxifen formation are upregulated. The route leading to endoxifen through the formation of 4OHTam may become more important as, in this route, other enzymes than CYP2D6 are involved (Fig. 1). Whether this magnitude of endoxifen increase is necessary to make tamoxifen most effective is uncertain; the critical effective endoxifen concentration is unknown, because prospective data are lacking. However, in one retrospective study, an endoxifen threshold of $5.97 \mathrm{ng} / \mathrm{ml}$ (=16.0 nM) was suggested [17]. All 11 PMs and 6 out of 12 IMs started with a baseline endoxifen level below this threshold. Our individualized endoxifen-guided dose escalation managed to increase endoxifen concentrations of all patients to a level above $16 \mathrm{nM}$ (Fig. 2). Nevertheless, Lash et al. postulated using a model that, even in PMs, tamoxifen and its metabolites are able to bind over $99.6 \%$ of estrogen receptors. Because of the abundance of tamoxifen and its metabolites at the estrogen receptor level regardless of the CYP2D6 genotype, PMs may unlikely have a clinically relevant smaller effect from tamoxifen than EMs [7, 32].Therefore, we are eagerly awaiting the results from the ongoing prospective studies, addressing the relation between endoxifen and clinical outcome in tamoxifen-treated breast cancer patients (CYPTAM: NTR1509; CYPTAMBRUT-2: NCT00965939; ECOG E3108: NCT01124695).

Tamoxifen dose escalation not only may increase efficacy, but may also increase toxicity. In the current study, an escalated dose up to $120 \mathrm{mg}$ was safe and did not significantly increase side effects. Toxicity, however, caused one patient to stop treatment with an escalated dose of $60 \mathrm{mg}$. Furthermore, long-term side effects are unknown as all patients returned to the normal $20 \mathrm{mg}$ tamoxifen dose after 2 months. The maximum tamoxifen dosage of $120 \mathrm{mg}$ that was considered safe was based on only a limited amount of studies in metastatic breast cancer and several studies in other advanced tumor types [18, 20-24]. Although the situation of tamoxifen used in other advanced tumor types sometimes combined with cytostatics is difficult to extrapolate to the early breast cancer patient using adjuvant tamoxifen, no severe toxicity was found in literature using up to $120 \mathrm{mg}$ during a short period of time. Tamoxifen retinopathy has been reported when using long-term high doses of tamoxifen (240-320 mg/day) in metastatic breast cancer, while ocular toxicity is uncommon in long-term, low-dose tamoxifen use, leaving uncertainty for doses from 40 up to $120 \mathrm{mg}$ [33, 34]. However, information on side effects such as endometrial cancer and venous tromboembolism as a result of long-term tamoxifen use at such high dosage is uncertain. As a proxy for the ability of tamoxifen to increase the risk of developing endometrial cancer, we aimed to determine concentrations of $\alpha$-hydroxytamoxifen, a potential carcinogenic metabolite. Increase of the $\alpha$-hydroxytamoxifen concentration as result of the tamoxifen dose escalation would potentially also impose an increased endometrial cancer risk. Unfortunately, we were not able to accurately quantify $\alpha$-hydroxytamoxifen, partly because of analyte instability.

In conclusion, a temporary CYP2D6 genotype- and endoxifen-guided tamoxifen dose escalation in CYP2D6 poor and intermediate metabolizers increased endoxifen concentrations without increasing short-term side effects. More than threefold endoxifen increase in PMs suggests upregulation of alternative routes for endoxifen formation. Whether such tamoxifen dose escalation is necessary to increase tamoxifen efficacy in PMs and IMs and whether it is safe in view of long-term toxic effects is unknown and needs to be further explored.

Acknowledgments We would like to thank the women participating in the CYPTAM trial, all collaborating hospitals, and local investigators and Roche for kindly providing the Amplichips.

\section{Compliance with ethical standards}

Conflict of interest The authors declare that they have no conflict of interest.

Open Access This article is distributed under the terms of the Creative Commons Attribution-NonCommercial 4.0 International License (http://creativecommons.org/licenses/by-nc/4.0/), which permits any noncommercial use, distribution, and reproduction in any medium, provided you give appropriate credit to the original author(s) and the source, provide a link to the Creative Commons license, and indicate if changes were made.

\section{References}

1. Goetz MP, Rae JM, Suman VJ, Safgren SL, Ames MM, Visscher DW et al (2005) Pharmacogenetics of tamoxifen biotransformation is associated with clinical outcomes of efficacy and hot flashes. J Clin Oncol 23:9312-9318

2. Stearns V, Johnson MD, Rae JM, Morocho A, Novielli A, Bhargava $\mathrm{P}$ et al (2003) Active tamoxifen metabolite plasma concentrations after coadministration of tamoxifen and the selective serotonin reuptake inhibitor paroxetine. J Natl Cancer Inst 95:1758-1764

3. Jin Y, Desta Z, Stearns V, Ward B, Ho H, Lee KH et al (2005) CYP2D6 genotype, antidepressant use, and tamoxifen metabolism during adjuvant breast cancer treatment. J Natl Cancer Inst 97:30-39

4. Schroth W, Goetz MP, Hamann U, Fasching PA, Schmidt M, Winter S et al (2009) Association between CYP2D6 polymorphisms and outcomes among women with early stage breast cancer treated with tamoxifen. JAMA 302:1429-1436

5. Schroth W, Hamann U, Fasching PA, Dauser S, Winter S, Eichelbaum M et al (2010) CYP2D6 polymorphisms as predictors of outcome in breast cancer patients treated with tamoxifen: expanded polymorphism coverage improves risk stratification. Clin Cancer Res 16:4468-4477. doi:10.1158/1078-0432.CCR-100478 
6. Dezentje VO, Guchelaar HJ, Nortier JW, van de Velde CJ, Gelderblom H (2009) Clinical implications of CYP2D6 genotyping in tamoxifen treatment for breast cancer. Clin Cancer Res $15: 15-21$

7. Lash TL, Lien EA, Sorensen HT, Hamilton-Dutoit S (2009) Genotype-guided tamoxifen therapy: time to pause for reflection? Lancet Oncol 10:825-833

8. Goetz M, Berry D, Klein T, International Tamoxifen Pharmacogenomics Consortium (2009) Adjuvant tamoxifen treatment outcome according to cytochrome P450 2D6 (CYP2D6) phenotype in early stage breast cancer: findings from the International Tamoxifen Pharmacogenomics Consortium. Cancer Res 69:33

9. Goetz MP, Schaid DJ, Wickerham DL, Safgren S, Mushiroda T, Kubo $M$ et al (2011) Evaluation of CYP2D6 and efficacy of tamoxifen and raloxifene in women treated for breast cancer chemoprevention: results from the NSABP P1 and P2 clinical trials. Clin Cancer Res 17:6944-6951. doi:10.1158/1078-0432. CCR-11-0860

10. Rae JM, Drury S, Hayes DF, Stearns V, Thibert JN, Haynes BP et al (2012) CYP2D6 and UGT2B7 genotype and risk of recurrence in tamoxifen-treated breast cancer patients. J Natl Cancer Inst 104:452-460. doi:10.1093/jnci/djs126

11. Regan MM, Leyland-Jones B, Bouzyk M, Pagani O, Tang W, Kammler R et al (2012) CYP2D6 genotype and tamoxifen response in postmenopausal women with endocrine-responsive breast cancer: the breast international group 1-98 trial. J Natl Cancer Inst 104:441-451. doi:10.1093/jnci/djs125

12. Dezentje VO, Van Schaik RH, Vletter-Bogaartz JM, Van der Straaten T, Wessels JA, Kranenbarg EM et al (2013) CYP2D6 genotype in relation to tamoxifen efficacy in a Dutch cohort of the tamoxifen exemestane adjuvant multinational (TEAM) trial. Breast Cancer Res Treat 140:363-373. doi:10.1007/s10549-0132619-6

13. Dezentje VO, Hartigh de J, Guchelaar H, Hessing T, Straaten van der T, Vletter-Bogaartz JM et al (2011) Association between endoxifen serum concentration and predicted CYP2D6 phenotype in a prospective cohort of patients with early-stage breast cancer. J Clin Oncol 29, 15(suppl; abstr 562):60s

14. Lim YC, Desta Z, Flockhart DA, Skaar TC (2005) Endoxifen (4hydroxy-N-desmethyl-tamoxifen) has anti-estrogenic effects in breast cancer cells with potency similar to 4-hydroxy-tamoxifen. Cancer Chemother Pharmacol 55:471-478

15. Lim YC, Li L, Desta Z, Zhao Q, Rae JM, Flockhart DA et al (2006) Endoxifen, a secondary metabolite of tamoxifen, and 4-OH-tamoxifen induce similar changes in global gene expression patterns in MCF-7 breast cancer cells. J Pharmacol Exp Ther 318:503-512

16. Wu X, Hawse JR, Subramaniam M, Goetz MP, Ingle JN, Spelsberg TC (2009) The tamoxifen metabolite, endoxifen, is a potent antiestrogen that targets estrogen receptor alpha for degradation in breast cancer cells. Cancer Res 69:1722-1727

17. Madlensky L, Natarajan L, Tchu S, Pu M, Mortimer J, Flatt SW et al (2011) Tamoxifen metabolite concentrations, CYP2D6 genotype, and breast cancer outcomes. Clin Pharmacol Ther 89:718-725. doi:10.1038/clpt.2011.32

18. Rose C, Theilade K, Boesen E (1982) Treatment of advanced breast cancer with tamoxifen: Evaluation of the dose-response relationship at two dose levels. Breast Cancer Research and Treatment 2(4):395-400. 1982 Date of Publication: 1982:395-400

19. Irvin WJ Jr, Walko CM, Weck KE, Ibrahim JG, Chiu WK, Dees EC et al (2011) Genotype-guided tamoxifen dosing increases active metabolite exposure in women with reduced CYP2D6 metabolism: a multicenter study. J Clin Oncol. doi:10.1200/JCO. 2010.31.4427

20. Trump DL, Smith DC, Ellis PG, Rogers MP, Schold SC, Winer EP et al (1992) High-dose oral tamoxifen, a potential multidrugresistance-reversal agent: phase I trial in combination with vinblastine. J Natl Cancer Inst 84:1811-1816

21. Stahl M, Wilke H, Schmoll HJ, Schober C, Diedrich H, Casper J et al (1992) A phase II study of high dose tamoxifen in progressive, metastatic renal cell carcinoma. Ann Oncol 3:167-168

22. McClay EF, McClay ME, Jones JA, Winski PJ, Christen RD, Howell SB et al (1997) A phase I and pharmacokinetic study of high dose tamoxifen and weekly cisplatin in patients with metastatic melanoma. Cancer 79:1037-1043. doi:10.1002/(SICI)10970142(19970301)79:5<1037:AID-CNCR22>3.0.CO;2-1

23. Perez EA, Gandara DR, Edelman MJ, O'Donnell R, Lauder IJ, DeGregorio M (2003) Phase I trial of high-dose tamoxifen in combination with cisplatin in patients with lung cancer and other advanced malignancies. Cancer Invest 21:1-6

24. Hansmann A, Adolph C, Vogel T, Unger A, Moeslein G (2004) High-dose tamoxifen and sulindac as first-line treatment for desmoid tumors. Cancer 100:612-620

25. The Netherlands National Trial Register (2010) http://www.trial register.nl/trialreg/admin/rctview.asp?TC=1509. Ref Type: Online Source

26. Borges S, Desta Z, Jin Y, Faouzi A, Robarge JD, Philips S et al (2010) Composite functional genetic and comedication CYP2D6 activity score in predicting tamoxifen drug exposure among breast cancer patients. J Clin Pharmacol 50:450-458

27. Kisanga ER, Gjerde J, Guerrieri-Gonzaga A, Pigatto F, PesciFeltri A, Robertson C et al (2004) Tamoxifen and metabolite concentrations in serum and breast cancer tissue during three dose regimens in a randomized preoperative trial. Clin Cancer Res 10:2336-2343

28. Teunissen SF, Rosing H, Koornstra RH, Linn SC, Schellens JH, Schinkel AH et al (2009) Development and validation of a quantitative assay for the analysis of tamoxifen with its four main metabolites and the flavonoids daidzein, genistein and glycitein in human serum using liquid chromatography coupled with tandem mass spectrometry. J Chromatogr B Analyt Technol Biomed Life Sci 877:2519-2529. doi:10.1016/j.jchromb.2009.06.029

29. Barginear MF, Jaremko M, Peter I, Yu C, Kasai Y, Kemeny M et al (2011) Increasing tamoxifen dose in breast cancer patients based on CYP2D6 genotypes and endoxifen levels: effect on active metabolite isomers and the antiestrogenic activity score. Clin Pharmacol Ther 90:605-611. doi:10.1038/clpt.2011.153

30. Kiyotani K, Mushiroda T, Imamura CK, Tanigawara Y, Hosono N, Kubo M et al (2012) Dose-adjustment study of tamoxifen based on CYP2D6 genotypes in Japanese breast cancer patients. Breast Cancer Res Treat 131:137-145. doi:10.1007/s10549-0111777-7

31. Davies C, Godwin J, Gray R, Clarke M, Cutter D, Darby S et al (2011) Relevance of breast cancer hormone receptors and other factors to the efficacy of adjuvant tamoxifen: patient-level metaanalysis of randomised trials. Lancet 378:771-784. doi:10.1016/ S0140-6736(11)60993-8

32. Dowsett M, Haynes BP (2003) Hormonal effects of aromatase inhibitors: focus on premenopausal effects and interaction with tamoxifen. J Steroid Biochem Mol Biol 86:255-263

33. Kaiser-Kupfer MI, Lippman ME (1978) Tamoxifen retinopathy. Cancer Treat Rep 62:315-320

34. Nayfield SG, Gorin MB (1996) Tamoxifen-associated eye disease. A review. J Clin Oncol 14:1018-1026 